\title{
ANALISIS IMPLEMENTASI SISTEM MANAJEMEN MUTU ISO 9001:2008 PADA SEKOLAH TINGGI ILMU ADMINISTRASI MANDALA INDONESIA
}

\author{
Dony Hendartho \\ Sekolah Tinggi Ilmu Administrasi Mandala Indonesia \\ dony.english@yahoo.co.id
}

\begin{abstract}
Implementation of Total Quality Management makes organization to maintain quality standards in all aspects of organization's business. Standard quality management system (QMS) that has been developed and suitable for education is ISO 9001, achievement of quality device that is expected to respond to the challenges of globalization by increasing the efficiency and effectiveness to satisfy stakeholders. Higher School of Administration Sciences of Mandala Indonesia (STIAMI) proved itself as a reliable organization that received the ISO 9001:2008 certificate issued by QS Zurich AG no. 7011 on April 19, 2011.

This research aims are (1) To determine the implementation of Quality Managements System ISO 9001:2008 from the aspect of dokumentation, (2) To determine the implementation of Quality Managements System ISO 9001:2008 from the aspect of management responsibility and alternative implementation strategies for corrective action.

The data used in the form of primary and secondary data, both from qualitative and quantitative. Processing of qualitative data using descriptive analysis is based on interviews with party organization consists of nine informen who master the Quality Management System and its implementation in STIAMI on the right target and can affect policy. The collected data is processed by the method of analytic hierarchy process AHP with Microsoft Excel 2010 software, version AHPcalc 12:08:13.

The results of data processing show that the essential elements of QMS ISO 9001:2008 in STIAMI are Quality Management System (25.8 \%), Responsibility Management (25\%), Product Realization (23.8\%), Measurement, Analysis \& Improvement (17, $4 \%$ ) and Resource Management (8\%); the most responsible actor is Top Management (51.4\%); goals to be achieved are the Quality Improvement Services (59.7 \%), Improvement of Administration (31.2 \%) and Reference (9.1\%); alternative measures such as Education and Training (1st priority), Monitoring and Evaluation (2nd priority) and Teamwork (3rd priority)

Based on this research, it can be concluded that the implementation of QMS ISO 9001:2008 in STIAMI is going well.
\end{abstract}

Keywords: quality, quality management system, ISO 9001:2008

Abstrak. Implementasi Total Quality Management membuat organisasi harus memelihara standar
mutu disegala aspek bisnis organisasi. Standar sistem manajemen mutu (SMM) yang telah
berkembang dan tepat untuk dunia pendidikan adalah ISO 9001, alat pencapaian tujuan mutu yang
diharapkan mampu menjawab tantangan globalisasi dengan cara meningkatkan efisiensi dan
efektifitas untuk memuaskan para stakeholder. Sekolah Tinggi Ilmu Administrasi Mandala
Indonesia (STIAMI) membuktikan diri sebagai organisasi yang andal yang meraih sertifikat ISO
9001:2008 yang dikeluarkan oleh QS Zurich dengan AG No. 7011 pada 19 April 2011. Penelitian
ini bertujuan (1) Untuk mengetahui implementasi Sistem Manajemen Mutu ISO 9001:2008 ditinjau
dari aspek dokumentasi: (2) Untuk mengetahui implementasi Sistem Manajemen Mutu ISO
9001:2008 ditinjau dari aspek tanggung jawab manajemen dan alternatife tindakan untuk perbaikan
strategi implementasi.
Data yang digunakan berupa data primer dan sekunder, baik kualitatif maupun kuantitatif.
Pengolahan data kualitatif menggunakan analisis deskriptif berdasarkan hasil wawancara dengan
pihak organisasi yang terdiri dari sembilan orang narasumber yang menguasai Sistem Manajemen
Mutu pada STIAMI dan implementasinya pada sasaran yang tepat serta memengaruhi kebijakan. 
Data yang terkumpul diolah dengan metode proses hierarki analitik PHA dengan bantuan perangkat lunak Microsoft Excel 2010, yaitu software AHPcalc version 12.08.13.

Hasil pengolahan data menunjukkan bahwa unsur-unsur penting SMM ISO 9001:2008 pada STIAMI adalah Sistem Manajemen Mutu (25,8 \%), Tanggung jawab Manajemen (25 \%), Realisasi Produk (23,8 \%), Pengukuran, Analisis \& Peningkatan (17,4 \%) dan Manajemen Sumber Daya (8 $\%)$; aktor yang paling berperan adalah Top Management $(51,4 \%)$; tujuan yang ingin dicapai adalah Peningkatan Mutu Pelayanan (59,7 \%), Perbaikan Administrasi (31,2 \%) dan Referensi (9,1 \%); alternatife tindakan berupa Pendidikan dan Pelatihan (prioritas 1), Monitoring dan Evaluasi (prioritas 2) dan Teamwork (prioritas 3).

Berdasarkan hasil penelitian tersebut, dapat disimpulkan bahwa implementasi SMM ISO 9001:2008 pada STIAMI berjalan dengan baik.

Kata kunci: Kualitas Sistem Manajemen Mutu, ISO 9001:2008

Perguruan Tinggi memiliki otonomi untuk mengelola sendiri lembaganya sebagai pusat penyelenggaraan Tridharma. Otonomi pengelolaan Perguruan Tinggi dilaksanakan sesuai dengan dasar dan tujuan serta kemampuan Perguruan Tinggi. Dasar dan tujuan serta kemampuan Perguruan Tinggi untuk melaksanakan otonomi dievaluasi secara mandiri oleh Perguruan Tinggi. Otonomi pengelolaan Perguruan Tinggi meliputi bidang akademik dan bidang nonakademik. Otonomi pengelolaan di bidang akademik meliputi penetapan norma dan kebijakan operasional serta pelaksanaan Tridharma

Otonomi pengelolaan di bidang nonakademik meliputi penetapan norma, kebijakan operasional serta pelaksanaan terkait organisasi, keuangan, kemahasiswaan, ketenagaan, dan sarana prasarana.

Mutu merupakan sebuah filosofi dan metodologi yang membantu institusi untuk merencanakan perubahan dan mengatur agenda dalam menghadapi tekanan eksternal yang berlebihan. Mutu didefinisikan sebagai sesuatu yang memuaskan dan melampaui keinginan dan kebutuhan pelanggan. Peningkatan mutu menjadi semakin penting bagi institusi yang digunakan untuk memperoleh kontrol lebih baik (Sallis, 2010: 15). Juran (Heizer \& Render, 1993: 12) mendefinisikan mutu sebagai kecocokan dalam penggunaan produk. Selanjutnya Juran (Atamadi, 2010: 28) menyatakan bahwa mutu sebagai hasil produksi, baik produksi barang maupun jasa berhasil memenuhi kepuasan pelanggan dan bebas cacat. Menurut Widodo (2011: 6), mutu merupakan gagasan dinamis yang sulit untuk diseragamkan. Di satu sisi, mutu dapat dipahami sebagai konsep absolut dan pada sisi lain dapat dipahami sebagai konsep relatif: (a) Konsep Absolut: Mutu akan menjadi simbul status bagi pelanggan internal maupun eksternal, sehingga stakeholder (pemilik) akan merasa bangga dan merasa puas, khususnya bagi orang tua peserta didik; (b) Konsep Relatif: Mutu sebagai konsep relatif, sangat mengikuti keinginan pelanggan yang menghasilkan keluaran (output) secara konseptual.

Sebenarnya mutu/kualitas telah dikenal sejak empat ribu tahun yang lalu, ketika bangsa Mesir Kuno mengukur dimensi batu-batu yang digunakan untuk membangun piramida. Namun seiring dengan perkembangan zaman dan revolusi industri, fungsi kualitas kemudian mengalami perkembangan seperti yang ditunjukkan pada Tabel 1.

Total Quality Management (TQM) atau Manajemen Mutu Terpadu (MMT) merupakan suatu pendekatan berorientasi pada pelanggan dengan memperkenalkan perubahan manajemen sistematik dan perbaikan terusmenerus terhadap proses, output dan pelayanan suatu organisasi (Widodo, 2011: 27). Marimin (2004: 51) menjelaskan bahwa MMT merupakan sistem manajemen yang mengikutsertakan seluruh anggota dalam organisasi dalam menerapkan konsep dan teknik kendali mutu untuk mendapatkan kepuasan pelanggan dan orang yang mengerjakan. Menurut Herber dan Webb (2010: 64), ada empat hakikat dari TQM. Keempat hakikat tersebut adalah: (a) Berfokus pada Pelanggan: Mencapai mutu berarti 
Tabel 1. Perkembangan Manajemen Kualitas

\begin{tabular}{cl}
\hline Tahun & \multicolumn{1}{c}{ Perkembangan Manajemen Kualitas } \\
\hline 1920-1940 & Kelompok kualitas yang utama adalah inspeksi.Para inspektor mengukur \\
& hasil produksi berdasarkan spesifikasi. \\
& Pada masa ini ditemukannya konsep statistik dalam hal pengendalian \\
& variabel-variabel produk, seperti panjang, lebar, berat, tinggi dan \\
& pengambilan sampel untuk menguji penerimaan produk yang diprakarsai \\
& oleh Walter A. Stewart, H.F. Dodge, dan H.G. Romig. \\
& Kelompok inspeksi berkembang menjadi pengendalian kualitas.Tanggung \\
& jawab kualitas dialihkan ke bagian quality control independen. \\
& Diperkenalkannya konsep total quality control yang pertama kali oleh \\
& Feigenbaum pada tahun 1960 yang kemudian dikembangkan menjadi total \\
& quality control organizationwide di tahun 1970 dan menjadi konsep total \\
& quality system pada tahun 1983. \\
& Pengendalian kualitas berkembang menjadi penjaminan kualitas yang \\
& berfokus kepada proses dan kualitas produk melalui pelaksanaan audit \\
& operasi, pelatihan analisis, kinerja teknis, dan petunjuk operasi untuk \\
& peningkatan kualitas. \\
& Aspek kualitas mulai di evaluasi melalui penerapan fungsi-fungsi \\
& manajemen kualitas. \\
& Diperkenalkannya konsep total quality management oleh Frederick Taylor \\
& pada tahun 1990-an, yang dikenal dengan sebutan Father of scientific \\
& Management dan terkenal dengan teorinya Time and Motion Studies.Total \\
Quality Management (TQM) berkembang menjadi Learning organization \\
yang menggunakan filosofi continous quality improvement dan \\
menggunakan konsep manajemen pengetahuan. \\
Dengan berkembangya teknologi informasi pada abad 20-an. Konsep \\
manajemen kualitas dibarengi dengan konsep e-learning atau electronics \\
learning.
\end{tabular}

Sumber: $\underline{\text { http://www.min-consulting }}$

memenuhi atau melebihi harapan pelanggan dengan kinerja dari produk atau jasa; (b) Melibatkan keseluruhan angkatan kerja dalam pengambilan keputusan; Unit pembuatan tindakan dan pengambilan keputusan biasa bukan seorang manajer individual, melainkan sebuah tim karyawan; (c) Komitmen terhadap perbaikan terus-menerus; Perbaikan terusmenerus hanya berarti tak pernah puas dengan kemenangan-kemenangan; (d) Rencana Tindakan; Rencana tindakan adalah kontrak yang menyatakan apa yang akan dilakukan pada waktu tertentu.

Implementasi TQM membuat organisasi harus memelihara standar mutu di segala aspek bisnis organisasi bersangkutan. Hal ini untuk memastikan bahwa segala sesuatu dikerjakan dengan benar sejak awal dan dapat mengurangi ataupun menghilangkan cacat (defect) dan pemborosan (waste) selama operasi (http://www.min-consulting, 15 Juli 2013). Inti dari implementasi standar mutu adalah terjaganya mutu hasil dari suatu produk, yaitu suatu sistem knowledge sharing yang memungkinkan setiap orang untuk menghasilkan hal sama dengan mutu sama, sehingga akan mengurangi ketergantungan terhadap satu orang (Wangtry, 2009: 8).

Manajemen mutu di bidang pendidikan adalah sesuatu model atau bentuk pengelolaan pendidikan dalam upaya reformasi pendidikan menuntut adanya dukungan dan keinginan pemerintah, dukungan dari warga sekolah dan warga masyarakat. Agar pendidikan tinggi memiliki standar baku yang ditetapkan organisasi internasional, perguruan tinggi yang 


\section{Evolution of ISO 9000 series}

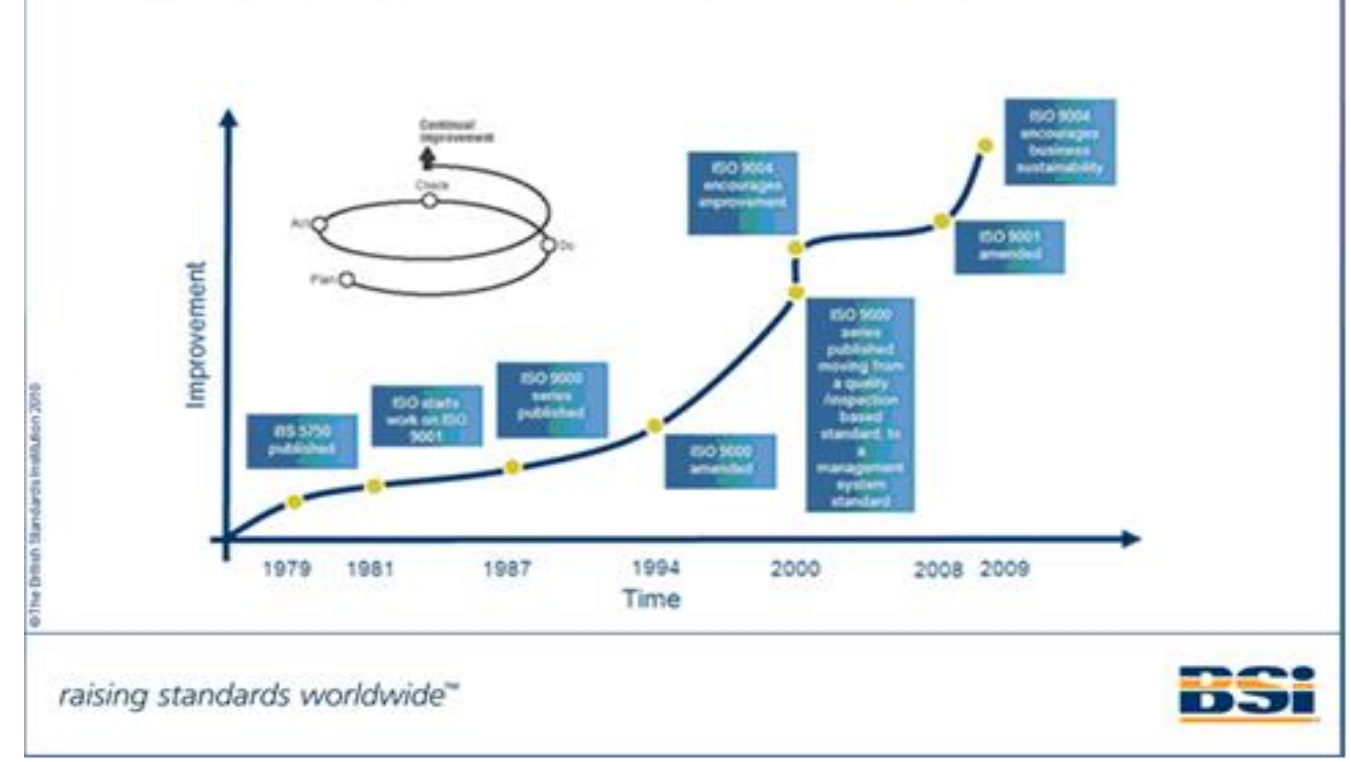

\section{Gambar 1. Evolution of ISO 9000 Series}

telah memiliki kriteria tertentu dimungkinkan untuk dapat memperoleh sertifikasi The International Organization for Standardization (ISO).

Salah satu standar sistem manajemen mutu (SMM) yang telah berkembang adalah ISO 9001. ISO 9001 versi 2000 dan versi 2008 lebih mengutamakan pada pola business process yang terjadi dalam organisasi perusahaan. Dengan demikian hampir semua jenis usaha dapat mengimplementasikan sistem manajemen mutu ISO 9001 ini. Versi 2008 adalah versi terbaru yang diterbitkan pada Desember 2008 lalu. ISO 9001:2008 lebih mengedepankan pada efektivitas proses dari suatu organisasi dalam melakukan proses corrective dan preventive action. Lihat gambar 1.

Dalam Widodo (2011: 35-36) dijelaskan bahwa versi ISO yang banyak disorot oleh dunia pendidikan adalah ISO 9000, yakni versi terbarunya dipublikasikan pada tahun 2008 meliputi empat seri, yaitu: (1) ISO 9000:2005 menguraikan dasar-dasar SMM dan merinci istilah-istilah yang digunakan dalam SMM; (2) ISO 9001:2008 merincikan persyaratan SMM suatu organisasi; (3) ISO 9004:2000 memberikan panduan untuk perbaikan berkelanjutan pada kinerja dan efisiensi menyeluruh pada organisasi; (4) ISO 1901:2002 memberikan panduan tentang pengauditan SMM dan audit manajemen lingkungan.

Sekolah Tinggi Ilmu Administrasi Mandala Indonesia (STIAMI) didirikan pada 27 Januari 1983 oleh dosen-dosen senior FISIP UI. Selama itu STIAMI telah mendapatkan kepercayaan dari pemerintah dan masyarakat dalam penyelenggaraan pendidikan tinggi karena mampu menghasilkan sumber daya manusia (SDM) yang berkualitas dan siap kerja. Hal ini selaras dengan kebijakan Menteri Pendidikan Nasional dalam meningkatkan mutu pendidikan tinggi di Indonesia. Di samping itu jajaran Departemen Pendidikan Nasional telah menerapkan kebijakan bahwa setiap unit utama organisasi baik unit kerja pusat maupun daerah untuk meraih sertifikat ISO 9001:2008. Tujuan implementasi standar adalah peningkatan kepuasan pelanggan melalui implementasi sistem secara efektif. Menurut Syukur (2010: 27-28), SMM ISO 9001:2008 menetapkan persyaratan untuk SMM yakni suatu organisasi harus menunjukkan kemampuannya dalam memberikan produk dan memenuhi persyaratan pelanggan dan pedoman hukum dan peraturan. Konsep dasar SMM ISO 9001:2008 adalah: (1) 


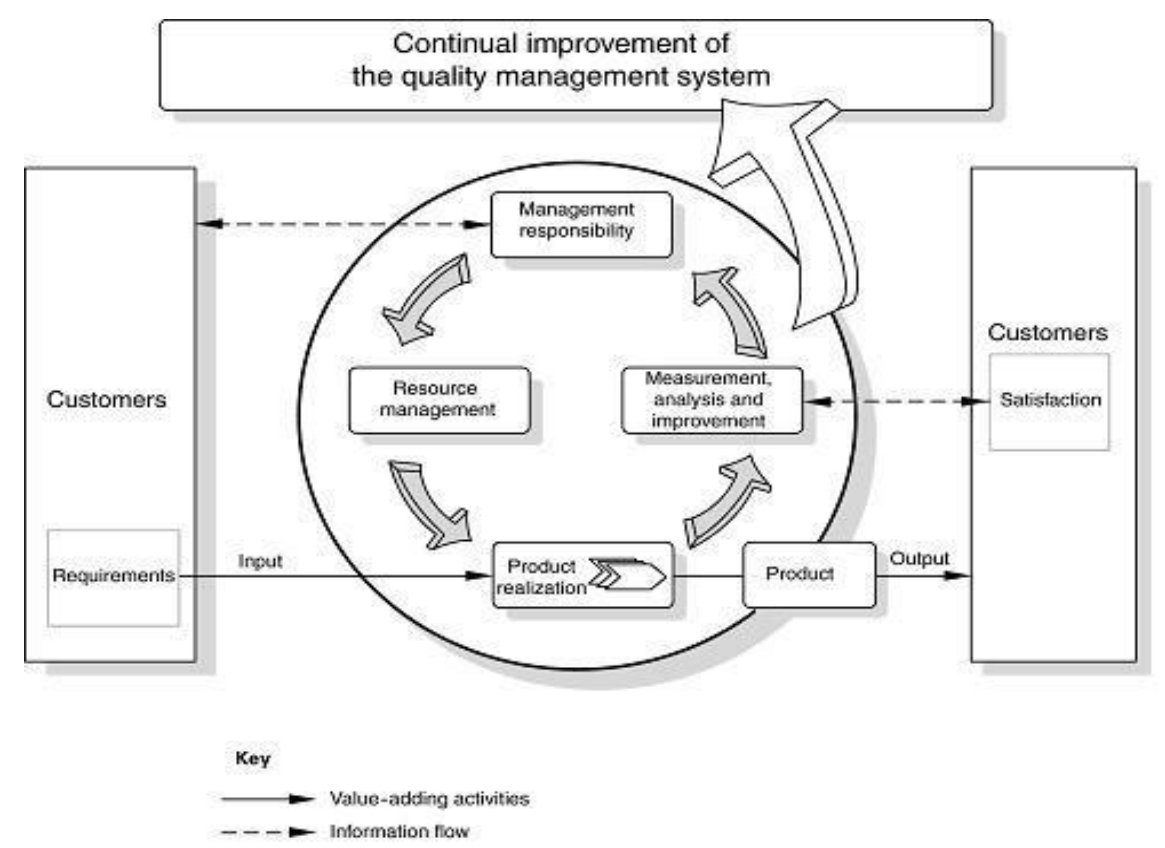

Gambar 2. Perbaikan berkelanjutan SMM

Perusahaan harus mempunyai standar sistem operasional yang jelas, untuk membantu karyawan untuk bekerja dengan output mutu yang baik; (2) Karyawan yang bekerja harus kompeten, sehingga dapat menghindari output ketidaksesuaian terhadap persyaratan produk sebagai akibat dari pekerjaan yang dilakukan oleh karyawan kurang kompeten; (3) Infrastrukutur yang dimiliki oleh perusahaan (gedung, peralatan kerja dan hardware maupun software) harus memadai untuk menghindari output mutu kurang baik akibat kurang memadainya infrastruktur perusahaan; (4) Perusahaan harus memiliki kebijakan mutu, sasaran mutu dan strategi untuk pencapaian sasaran mutu; (5) Perusahaan harus melakukan review secara berkala terhadap kinerja internal perusahaan, tingkat kepuasan pelanggan dan pencapaian sasaran mutu; (6) Perusahaan harus melakukan tindakan perbaikan atas penyimpangan yang terjadi (Corrective and Preventife Action atau CAPA), mempunyai program peningkatan secara terus-menerus (Continuous Improvement). Lihat gambar 2.

Menurut Widodo (2011: 34), penerapan SMM ISO dalam dunia pendidikan pada dasarnya sama dengan penerapan ISO pada organisasi lain. (Tabel 2).
Oleh sebab itu, sistem penjamin mutu internal (SPMI) yang dimiliki oleh STIAMI diarahkan untuk menghasilkan mutu penyelenggaraan pendidikan yang sesuai Visi \& Misi STIAMI. SPMI STIAMI sebagai pelaksana penjamin mutu STIAMI berupaya menata dan mengembangkan sistem penjamin mutu yang telah ada agar dapat memberikan kontribusi dalam peningkatan mutu pendidikan di STIAMI di antaranya dengan mengimplementasikan SMM ISO 9001:2008.

Sekolah Tinggi Ilmu Administrasi Mandala Indonesi (STIAMI) Jakarta yang telah berhasil menjalankan SMM dan diakui secara internasional dengan mendapatkan sertifikat ISO 9001:2008 dari QS Zurich AG No. 7011 pada 19 April 2011 dan sekaligus telah melalui tahapan conformity (kesesuaian). Pada April 2012, STIA Mandala Indonesia juga telah melewati First Surveillance, yaitu tahapan consistency (konsistensi) dengan beberapa cacatan perbaikan. Dan pada April 2013 lalu, STIA Mandala Indonesia juga telah melewati Second Surveillance, yaitu tahapan improvement (kemajuan) juga dengan beberapa catatan perbaikan. Hingga saat ini, STIAMI telah mengimplementasikan ISO 9001:2008 selama 3 tahun dengan beberapa catatan perbaikan dan perlu dilakukan penelitian untuk 
Tabel 2. Karakteristik ISO pada Dunia Pendidikan.

\begin{tabular}{|c|c|c|}
\hline No & Karakteristik ISO & Terjemahan untuk Pendidikan. \\
\hline 1. & $\begin{array}{l}\text { Tanggungjawab } \\
\text { Manajemen }\end{array}$ & Komitmen Manajemen terhadap mutu. \\
\hline 2. & Sistem Mutu & Sistem Mutu. \\
\hline 3. & Kontrak & $\begin{array}{l}\text { Kontrak dengan pelanggan internal } \\
\text { dan eksternal. }\end{array}$ \\
\hline 4. & Kontrol Dokumen & Kontrol dokumen. \\
\hline 5. & Pengadaan Bahan & Kebijakan seleksi dan ujian masuk. \\
\hline 6. & Persediaan Produk & Layanan pendukung bagi peserta didik, \\
\hline 7. & Identifikasi Produk & Catatan kemajuan peserta didik. \\
\hline 8. & Kontrol Proses & Pengembangan design dan penyampaian \\
\hline 9. & Inspeksi dan Tes & Penilaian dan Tes \\
\hline 10. & $\begin{array}{l}\text { Perlengkapan, } \\
\text { inspeksi, pengukuran, } \\
\text { dan tes }\end{array}$ & Konsistensi metode penilaian \\
\hline 11. & $\begin{array}{c}\text { Status inspeksi dan } \\
\text { Tes }\end{array}$ & Prosedur dan catatan penilaian \\
\hline 12. & $\begin{array}{l}\text { Kontrol produk yang } \\
\text { tidak sesuai }\end{array}$ & $\begin{array}{l}\text { Metode dan prosedur diagnostik untuk } \\
\text { mengidentifikasi kegagalan dan }\end{array}$ \\
\hline 13. & Tindakan Perbaikan & $\begin{array}{l}\text { Tindakan perbaikan terhadap peserta } \\
\text { didik dan sistem dalam menghadapi } \\
\text { tuntutan masyarakat. }\end{array}$ \\
\hline 14. & $\begin{array}{l}\text { Penanganan } \\
\text { pengamanan, } \\
\text { pengepakan dan } \\
\text { penyampain }\end{array}$ & $\begin{array}{l}\text { Fasilitas dan lingkungan fisik, bentuk } \\
\text { tawaran lain seperti fasilitas olahraga, } \\
\text { kelompok, ekstrakurikuler, osis dan } \\
\text { fasilitas pembelajaran. }\end{array}$ \\
\hline 15. & Catatan Mutu & Catatan mutu. \\
\hline 16. & Audit Mutu Internal & Proses pengesahan audit mutu. \\
\hline 17. & Pelatihan & $\begin{array}{l}\text { Pelatihan dan pengembangan staf yang } \\
\text { mencakup prosedur-prosedur untuk } \\
\text { menilai kebutuhan pelatihan dan }\end{array}$ \\
\hline 18. & $\begin{array}{c}\text { Teknik-teknik } \\
\text { Statistik }\end{array}$ & Metode Review dan monitoring. \\
\hline
\end{tabular}

mengetahui strategi yang akan dilakukan dalam implementasi ISO 9001:2008 selanjutnya. Karena ISO 9001:2008 baru dimplementasikan di kampus pusat dan belum diimplementasikan di kampus-kampus unit. Tetapi apabila dilihat keadaan/kondisi STIAMI sebelum mengimplementasikan ISO 9001:2008, keadaan/ kondisi STIAMI sudah jauh lebih membaik. Meskipun demikian, implementasi ISO ini masih menemukan beberapa kendala.

Faktor penghambat implementasi Sistem Manajemen Mutu ISO 9001:2008 di STIAMI Jakarta, yaitu kurangnya komitmen manajemen puncak atau top management dalam implementasi ISO 9001:2008. Ini terjadi di awal tahun pengimplementasian, yaitu tahun 2010 sebelum mendapatkan sertifikat ISO. Kurangnya konsistensi dalam menjalankan prosedur ISO juga menjadi penghambat, walaupun sudah mengimplementasikan prosedur ISO, terkadang tetap menggunakan sistem lama, mutu yang sudah baik sulit untuk ditingkatkan.

Pelatihan dan persiapan yang telah diberikan kepada para karyawan kurang berjalan secara efektif dan tidak berkala. Pelatihan hanya dilakukan sebelum mendapatkan sertifikat ISO, setelah itu tidak 
ada pelatihan yang dilakukan secara berkala, sehingga pemahaman ISO pada level Operational atau Low Management (staf) belumlah maksimal.

Tanggung jawab manajemen dari setiap bagian masih sangat kurang, contohnya adanya prosedur mutu yang seharusnya dijadikan acuan dalam bekerja tetapi tidak dilakukan dan bahkan prosedur mutu tidak memiliki arti dalam kegiatan bekerja. Teamwork (kerja sama) antarbagian masih sangat kurang. Contoh: harus adanya SOP yang mencakup antarbagian, akan tetapi SOP tersebut tidak dibuat.

Program Audit Internal belum mencakup informasi dan sumber daya yang diperlukan untuk mengatur dan melakukan audit yang efektif dan efisien. Keseriusan pada pihakpihak terkait dalam melakukan Internal Audit masih kurang maksimal. Sehingga efektivitas yang tadinya sangat diharapkan berjalan dengan baik, tidak berjalan seperti yang diharapkan.

Management Representative (MR) sebagai konsultan pelaksana ISO 9001:2008 di dalam struktur organisasi masih berada dalam bagian Sistem Penjamin Mutu Internal (SPMI). Komunikasi yang kurang maksimal juga terjadi antara Management Representative dan SPMI dengan bagian-bagian yang ada pada STIAMI mengenai implementasi ISO 9001:2008.

Kurang teroganisasinya pendokumentasian dan perekaman kegiatan. Dokumen-dokumen atau kearsipan ISO 9001:2008 yang tidak tersusun secara rapi dan sesuai standar terjadi di beberapa bagian kerja. Fasilitas penunjang yang mendukung kegiatan administrasi kampus belum maksimal seperti yang diharapkan. Hal ini dapat diwujudkan dalam bentuk sistem pelayanan yang terintegrasi seperti: SAPUA.

Kesiapan lembaga untuk maju ke tahap selanjutnya belumlah maksimal. Tahap pertama adalah kesesuaian (2011), kedua adalah konsistensi (2012), dan ketiga adalah improvement (2013). Terutama pada tahap kedua yaitu konsistensi. Dan secara keseluruhan Implementasi ISO 9001:2008 belum meningkatkan mutu produk secara signifikan.

\section{METODE PENELITIAN}

Dalam penelitian ini, peneliti akan menganalisis entitas-entitas implementasi Sistem Manajemen Mutu ISO 9000:2008 di STIAMI Pusat Jakarta yang khususnya ditinjau dari aspek dokumentasi dan aspek tanggung jawab manajemen. Penelitian ini menggunakan pendekatan kualitatif. Peneliti melakukan observasi dan wawancara. Selain itu, peneliti juga melihat dokumentasi internal perusahaan. Hasil analisis ini menginformasikan bagaimana implementasi ISO 9001:2008 pada STIAMI Jakarta dan dilakukan identifikasi strategi implementasi ISO 9001:2008 melalui kajian implementasi kalusul-klausul ISO 9001:2008. Alat analisis yang digunakan dalam identifikasi implementasi ISO 9001:2008 adalah Analisis Hierarki Proses (AHP).

Dalam penulisan ini, peneliti telah menguji keabsahan data dengan menggunakan beberapa kriteria: (1) Kredibilitas (Credibility); (a) Perpanjangan pengamatan; (b) Ketekunan dalam penelitian; (c) Triangulasi (cek ulang data supaya akurat/valid, baik sumber, tehnik dan waktu), (d) Ketercukupan Referensial, (e) Member check; (2) Keteralihan (Transferability), penulis memberikan deskripsi yang tebal untuk membuat seseorang merasa tertarik dalam membuat transfer. Dan hasil penelitian bisa digunakan di tempat lain: (1) Kebergantungan (Dependability). Peneliti melakukan pemeriksaan dependibilitas dengan cara melakukan audit terhadap keseluruhan proses penelitian; (2) Ketegasan (Confirmability), menguji konfirmability berarti menguji hasil penelitian dikaitkan dengan proses yang dilakukan. Munculnya hasil karena adanya proses. Lihat Tabel 3.

Penelitian dilakukan pada STIAMI Jakarta, bertempat di Jalan Pangkalan Asem Raya No. 55 Cempaka Putih Jakarta Pusat. Pemilihan lokasi ini berdasarkan pertimbangan bahwa STIAMI Pusat Jakarta telah mendapatkan sertifikat ISO 9001:2008 Zurich Swiss pada 26 April 2011, sehingga dianggap cukup relevan untuk pengkajiannya, serta kesediaan Satuan Penjamin Mutu Internal (SPMI) STIAMI Jakarta menyediakan tempat penelitian dan memberikan data yang diperlukan. Penelitian dimulai pada bulan April - Juni 2013 dan 
Tabel 3 Jenis dan deskripsi data

\begin{tabular}{|c|c|}
\hline Jenis Data & Deskripsi Data \\
\hline 1. Data Primer & $\begin{array}{l}\text { Implementasi dan } \\
\text { strategi implementasi } \\
\text { ISO 9001:2008. } \\
\text { Kriteria masalah, aktor, } \\
\text { penyebab masalah dan } \\
\text { alternatif tindakan. }\end{array}$ \\
\hline 2. Data Sekunder & $\begin{array}{l}\text { - Gambaran umum organisasi. } \\
\text { - Doku me n Implementasi ISO } \\
\text { 9001:2008. } \\
\text { - Tinjauan Pustaka }\end{array}$ \\
\hline 3. Kualitatif & $\begin{array}{l}\text { - Implementasi ISO 9001:2008. } \\
\text { - Identifikasi strategi. }\end{array}$ \\
\hline 4. Kuantitatif & $\begin{array}{l}\text { Data prioritas kriteria, aktor, } \\
\text { dan alternatif tindakan. }\end{array}$ \\
\hline
\end{tabular}

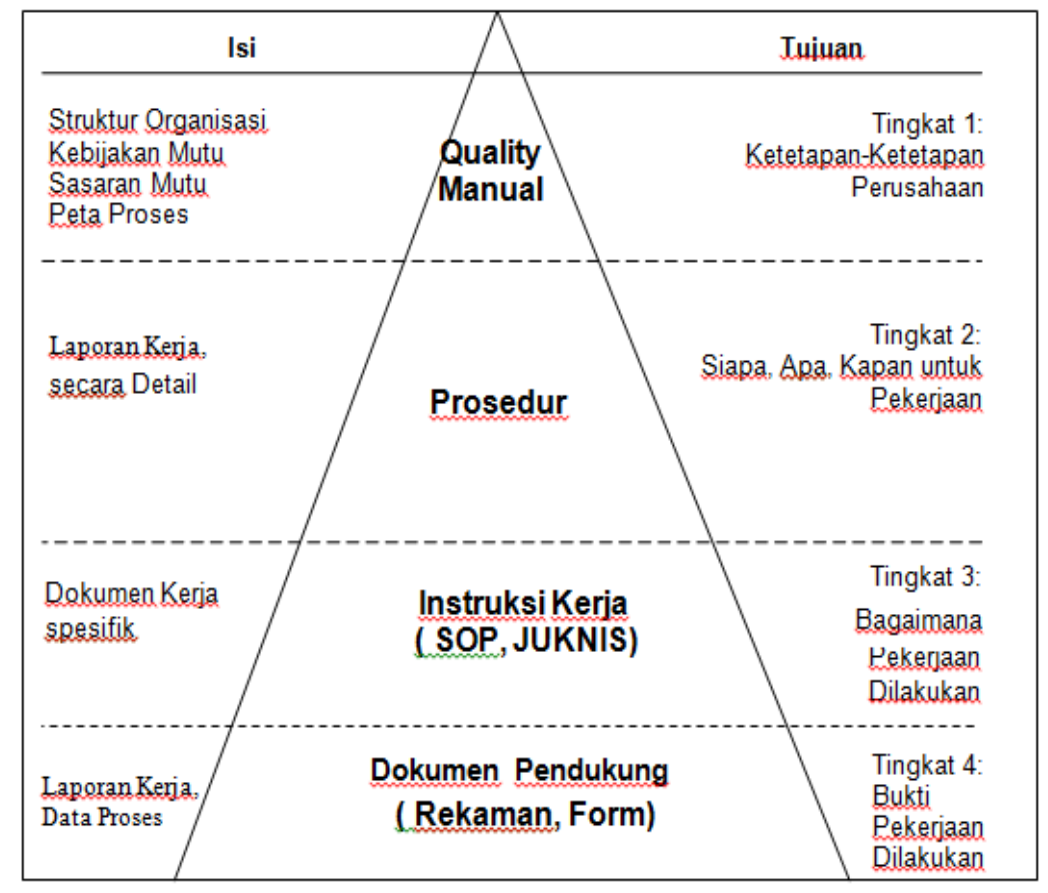

\section{Gambar 3. Hierarki Dokumentasi}

diperpanjang sejak bulan Juli - Agustus 2013. Ini dilakukan karena menyangkut kredibilitas data.
Implementasi SMM ISO 9001:2008 di STIAMI Aspek Dokumentasi (Klausal Manajemen Mutu), mencakup: (1) Persyaratan Umum; 
Institusi menerapkan sistem manajemen mutu dengan mengikuti aturan-aturan dasar, yang meliputi sistem dokumentasi, pemeliharaan, dan pengembangan sistem manajemen mutu. STIAMI mendokumentasikan sistem manajemen mutu yang terdiri dari empat tingkat hierarki dokumentasi, yaitu : lihat gambar 3; (2) Persyaratan Dokumentasi; Institusi menetapkan dan memelihara Pedoman Mutu yang berisi: (2) Ruang lingkup Sistem Manajemen Mutu dan penjelasan-penjelasan persayaratan ISO 9001:2008 yang relevan bagi STIAMI, (b) Prosedur-prosedur yang disyaratkan ISO 9001:2008; (c) Penjelasan interaksi antarproses Sistem Manajemen Mutu.

Institusi menyusun dan memelihara Prosedur Pengendalian Dokumen untuk menjamin dokumen yang berlaku dan beredar adalah dokumen yang benar, yang berisi: (a) Management Representative meninjau pedoman mutu sekurang-kurangnya satu tahun sekali; (b) Sejauh diperlukan, Management Representative bertanggung jawab atas peninjuan ulang dan perubahan dokumen; (c) Revisi Dokumen dilakukan dengan menggantikan halaman yang berubah, dan memberikan nomor dan tanggal revisi yang berlaku, serta menyertakan Lembar Status Perubahan yang berisi perubahanperubahannya; (d) Management Representative bertanggung jawab atas pendistribusian pedoman mutu yang telah direvisi dan dokumen Sistem Manajemen Mutu; (e) Setiap Pimpinan di STIAMI atau Kepala Bagian di STIAMI memastikan bahwa dokumen yang tersedia di tempat kerja adalah dokumen dengan status revisi terakhir, dan menjamin dokumen-dokumen itu mudah dibaca dan dicari kembali saat diperlukan; (f) Setiap Pimpinan di STIAMI atau Kepala Bagian di STIAMI dan Management Representative bertanggung jawab atas identifikasi dokumen eksternal serta pengendalian distribusinya; (g). Semua pemegang salinan Pedoman Mutu dan dokumen Sistem Manajemen Mutu harus memiliki edisi terakhir dan revisi terbaru serta mengembalikan/memusnahkan terbitan atau halaman kadaluarsa pada Management Representative.

Institusi menetapkan dan memelihara prosedur Pengendalian Rekaman yang memuat: (a) Management Representative dan setiap Pimpinan/Waka di STIAMI atau Kepala Bagian di STIAMI bertanggung jawab atas pemeliharaan rekaman, sebagai bukti aktivitas dan data yang dibutuhkan oleh Sistem Manajemen Mutu; (b) Management Representative dan setiap Pimpinan/Waka di STIAMI atau Kepala Bagian di STIAMI memastikan semua rekaman mudah dibaca dan disimpan dengan baik; (c) Aturan-aturan tentang pengendalian rekaman yang meliputi identifikasi, masa penyimpanan, perlindungan dan pembuangan rekaman

Aspek Tanggung Jawab Manajemen, Mencukupi: (1) Komitmen Manajemen: Pedoman ini menjelaskan komitmen manajemen dalam mengembangkan dan menjalankan sistem manajemen mutu, serta meningkatkan efektivitas penerapannya secara kontinu, dengan cara-cara seperti berikut: (a) Ketua bertanggungjawab untuk menyampaikan pentingnya memenuhi persyaratan pelanggan serta memenuhi peraturan perundang-undang yang berlaku ke setiap karyawan, (b) Ketua bertanggung jawab dalam merumuskan Kebijakan Mutu dan menetapkan Sasaran Mutu, (c) Ketua bertanggung jawab untuk menilai efektivitas penerapan Sistem Manajemen Mutu dengan mengadakan Tinjauan Manajemen, (d) Ketua bertanggung jawab menyediakan sumber daya yang cukup untuk mendukung sistem manajemen mutu; (e) Management Representative bertanggung jawab terhadap sosialisasi kebijakan mutu dan penerapan sistem manajemen mutu, (2). Fokus Pelanggan: Ketuabertanggung jawab untuk mengidentifikasi dan meninjau persyaratan pelanggan untuk memastikan bahwa Institusi benar-benar mampu memenuhi persyaratan pelanggan. Penetapan persyaratan yang berhubungan dengan produk (Klausul 7.2.1) : (a) Institusi bertanggung jawab mengadakan hubungan dengan pelanggan dan mendokumentasikan persyaratan pelanggan, dan peraturan hukum yang berhubungan dengan Institusi pendidikan; (b) Institusi mengadakan evaluasi untuk memastikan bahwa Institusi benar-benar mampu 
melaksanakan order yang diterima dari pelanggan; (c) Institusi mengidentifikasi dan memenuhi kebutuhan dan harapan pelanggan yang bertujuan untuk mencapai kepuasan pelanggan; (d) Pelanggan bagi STIAMI adalah Mahasiswa.

Kepuasan pelanggan (Klausul 8.2.1.): (a) Institusi mengidentifikasi dan menganalisis informasi yang berhubungan dengan tanggapan pelanggan terhadap tingkat pemenuhan persyaratan pelanggan; (b) Institusi menetapkan metode untuk mengukur tingkat kepuasan pelanggan; (c) Institusi selalu memperbaiki dan meningkatkan kinerja setiap bagian dalam memberikan kontribusi terhadap kepuasan pelanggan.

1) Kebijakan Mutu: Ketua bertanggung jawab dalam merumuskan kebijakan mutu yang sesuai dengan kondisi Institusi, dan memastikan bahwa Kebijakan mutu: a) sesuai dengan tujuan Institusi, b) memuat komitmen untuk memenuhi persyaratan dan meningkatkan mutu secara terus-menerus, c) menyediakan landasan atau kerangka bagi penetapan dan peninjauan sasaran mutu; d) dipahami di semua tingkat dan fungsi dalam Institusi, e) dikaji ulang untuk memastikan kesesuaiannya: (2) Perencanaan Mutu: a) Sasaran Mutu: Ketua bertanggung jawab dalam menetapkan sasaran mutu yang dituangkan dalam Rencana Manajemen (Business Plan): (1) Sasaran Mutu ditetapkan untuk setiap fungsi dan tingkatan yang relevan; (2) Sasaran Mutu dapat diukur dan konsisten dengan Kebijakan Mutu; b) Perencanaan Sistem Manajemen Mutu: (1) Pembantu Ketua bertanggung jawab untuk melaksanakan sasaran mutu pada seluruh tingkat dan fungsi dalam Institusi. Setiap Pembantu Ketua terkait bertanggung jawab mengoordinasikan rencana manajemen mutu di bagiannya masing-masing, (2) Memelihara integritas Sistem Manajemen Mutu bila terjadi perubahan Sistem Manajemen Mutu; 3) Tanggung Jawab, Wewewang, dan Komunikasi: a) Tanggung jawab dan wewenang bagi personil yang mengelola, melaksanakan, dan memverifikasi pekerjaan yang mempengaruhi mutu dimuat pada dokumen mengenai uraian jabatan (job desc.) yang disimpan di Bagian SDM, b) Management
Representative: (1) Ketua menunjuk Management Representative yang bertanggung jawab terhadap pelaksanaan sistem manajemen mutu yang memenuhi persyaratan ISO 9001, (2) Melaporkan kinerja Sistem Manajemen Mutu dan perbaikan yang diperlukannya kepada Ketua: c) Komunikasi Intern: Institusi menjamin bahwa komunikasi dalam perusahan berfungsi efektif, melalui kegiatankegiatan berikut: (1) Ucapan Salam ketika masuk kerja, (2) Pertemuan umum untuk seluruh karyawan; (3) Rapat kerja, (4) Memo dan pengumuman-pengumuman, 4) Tinjauan Manajemen: a) Umum: (1) Ketua bertanggung jawab atas pelaksanaan Tinjauan Manajemen untuk menilai efektivitas sistem manajemen mutu, yang dijadwalkan sekurang-kurangnya 2 (dua) kali dalam satu tahun, (2) Tinjauan Management membahas perubahan Visi dan Misi Institusi, Kebijakan Mutu, dan Sasaran Mutu Institusi untuk memenuhi kebutuhan dan peningkatan berlanjut;,(3) Rekaman hasil Tinjauan Manajemen harus disimpan dan dipelihara; b) Masukan Tinjauan: Agenda pembahasan dalam Tinjauan Manajemen harus meliputi: (1) Laporan Audit, (2) Umpan balik dari pelanggan, (3) Kinerja proses dari kesesuaian produk, (4) Status tindakan koreksi dan pencegahan, (5) Tindak lanjut dari tinjauan manajemen sebelumnya, (6) Perubahan yang dapat memengaruhi kinerja Sistem Manajemen Mutu, (7) Saran-saran; c). Keluaran Tinjauan: Hasil Tinjauan Manajemen harus menjadi masukan bagi: (1) Peningkatan proses Sistem Manajemen Mutu, (c) Perbaikan mutu Institusi, (3) Kebutuhan akan Sumber Daya.

\section{Penyusunan Struktur Hierarki}

Model struktur hierarki yang digunakan dalam penelitian ini terdiri dari lima tingkat. Tingkat pertama adalah fokus atau goals, yaitu strategi implementasi SMM ISO 9001:2008 pada STIAMI. Pemilihan fokus ini bertujuan untuk mengetahui prioritas alternatif yang dilakukan untuk membuat efektif implementasi ISO 9001:2008 pada STIAMI. Pemilihan fokus ini juga sebagai bentuk pemenuhan kebijakan Departemen Pendidikan Nasional dan sertifikat ISO 9001:2008 yang harus dipertahankan melalui surveillance audit. 
Tabel 4 Susunan Prioritas Factor/Unsur

\begin{tabular}{lcc}
\hline \multicolumn{1}{c}{ Unsur } & Bobot & Prioritas \\
\hline SMM & $25,8 \%$ & 1 \\
Tanggungjawab Manajemen & $25,0 \%$ & 2 \\
Realisasi Produk & $23,8 \%$ & 3 \\
Pengukuran, Analisis dan Peningkatan & $17,4 \%$ & 4 \\
Manajemen Sumber Daya & $8,0 \%$ & 5 \\
\hline
\end{tabular}

Sumber: Hasil analisis AHP

Pada tingkat dua adalah unsur yang terdiri dari lima faktor, yaitu SMM, tanggung jawab manajemen, manajemen sumber daya, realisasi produk, serta analisis, pengukuran dan peningkatan. Kelima faktor tersebut merupakan unsur-unsur yang terdapat SMM ISO 9001:2008

Tingkat ketiga adalah actor yang terdiri dari top management, middle management dan low management. Peran aktor-aktor tersebut sangat penting dalam implementasi ISO 9001:2008, karena masing-masing memiliki tingkat kepentingan berbeda. Pemilihan ketiga actor tersebut berdasarkan tingkatan organisasi dalam STIAMI.

Pada tingkat keempat merupakan tujuan (object) yang sesuai dengan permasalahan dalam implementasi SMM ISO 9001:2008 pada STIAMI Jakarta. Hal ini terdiri dari peningkatan mutu pelayanan, perbaikan administrasi dan referensi. Ketiga tujuan tersebut merupakan hasil analisis berdasarkan diskusi dan studi literatur.

Tingkat kelima adalah alternatif tindakan (alternative) yang dapat diambil untuk strategi implementasi SMM ISO 9001:2008 di STIAMI Jakarta agar berjalan efektif dan efisien. Ketiga tujuan yang telah dirumuskan sebelumnya diperoleh beberapa alternatif, namun belum menjadi prioritas utama. Alternatif tersebut adalah pendidikan dan pelatihan (Diklat), monitoring dan evaluasi (Monev), dan teamwork (kerja sama).

\section{ANALISIS \& INTERPRETASI PENELITIAN}

Hasil pengolahan pada level dua (faktor/unsur) menunjukkan bahwa unsur-unsur SMM ISO 9001:2008 yang ada pada STIAMI adalah Sistem Manajemen Mutu (25,5 \%), Tanggung jawab Manajemen (25,0 \%), Manajemen Sumber Daya $(8,0 \%)$, Realisasi Produk (23,8 \%), dan Pengukuran, Analisis \& Peningkatan $(17,4 \%)$, seperti yang terlihat pada Tabel 4.

Dari kelima unsur tersebut dapat diketahui unsur utama yang perlu diperhatikan dalam implementasi SMM ISO 9001:2008 dengan memilih nilai bobot tertinggi sebagai prioritas utama.

Dengan demikian SMM menjadi unsur utama yang mendapatkan perhatian lebih dibandingkan dengan unsur-unsur SMM ISO 9001:2008 lainnya. Unsur ini menjadi penting karena menetapkan kerangka kerja untuk proses peningkatan mutu lebih lanjut dengan membakukan proses guna memastikan konsistensi dan mampu menelusuri serta meningkatkan hubungan antarfungsi yang memengaruhi mutu, sehingga produk yang dihasilkan dapat terjaga.

Unsur terpenting berikutnya adalah Tanggung jawab Manajemen, unsur ini menjadi penting karena unsur ini menjamin SMM yang ada berlangsung dengan baik.

Kemudian, realisasi produk menempati peringkat ketiga. Hal ini dikarenakan unsur ini merupakan bagaimana STIAMI mendefinisikan proses realisasi produk yang efektif, sehingga produk yang dihasilkan mempu memenuhi kepuasan setiap stakeholder.

Hasil pengolahan pada level tiga (aktor) menunjukkan bahwa aktor yang berperan dalam implementasi ISO 9001:2008 secara berurutan adalah Top Management (51,4 \%), Middle Management $(37,0 \%)$ and Low Management (11,7\%), seperti pada Tabel 5. 
Tabel 5 Susunan prioritas aktor

\begin{tabular}{ccc}
\hline Aktor & Bobot & Prioritas \\
\hline Top Management & $51,4 \%$ & 1 \\
Middle Management & $37,0 \%$ & 2 \\
Low Management & $11,7 \%$ & 3 \\
\hline
\end{tabular}

Sumber: Hasil analisis AHP

Tabel 6 Susunan prioritas tujuan

\begin{tabular}{ccc}
\hline Tujuan & Bobot & Prioritas \\
\hline Peningkatan Mutu Pelayanan & $59,7 \%$ & 1 \\
Perbaikan Administrasi & $31,2 \%$ & 2 \\
Referensi & $9,1 \%$ & 3 \\
\hline Sumber: Hasil anais AHP &
\end{tabular}

Sumber: Hasil analisis AHP

Aktor utama yang bertanggungjawab dalam implementasi SMM ISO 9001:2008 ini dapat dipilih berdasarkan nilai bobot yang terbesar hingga yang rendah. Dengan demikian top management merupakan aktor terpenting dalam implementasi SMM ISO 9001:2008.

Top management mempunyai peranan yang terpenting dalam pelaksanaan SMM ISO 9001:2008 pada STIAMI. Hal ini dikarenakan semua keputusan yang akan dijalankan organisasi harus berada di bawah persetujuan adalah top management, serta bertugas untuk mengelola kegiatan manajemen mutu baik pada bidang akademik (pendidikan, penelitian, dan pengabdian kepada masyarakat) maupun nonakademik (administrasi dan manajemen). Selanjutnya pihak midlle management akan mengin-terpretasikan kebijakan-kebijakan yang telah diputuskan oleh top management. Setelah kebijakan diinterpretasikan oleh middle management, pihak low management akan melaksanakan kebijakan yang diputuskan sesuai ketentuan yang telah disahkan.

Hasil pengolahan pada level empat (tujuan) menunjukkan bahwa secara berurutan tujuan yang ingin dicapai melalui implementasi ISO 9001:2008 adalah peningkatan mutu pelayanan $(59,7 \%)$, perbaikan administrasi $(31,2 \%)$ dan referensi $(9,1 \%)$ seperti yang terlihat pada Tabel 6.
Pemilihan tujuan utama dilakukan sama seperti yang lain, yaitu memilih nilai bobot dari yang tertinggi. Disimpulkan bahwa peningkatan mutu pelayanan menduduki prioritas pertama STIAMI melalui implementasi SMM ISO 9001:2008, ingin menjamin mutu produk dan memenuhi kepuasan pelanggan dengan meningkatkan mutu STIAMI dalam pelayanan terhadap users di STIAMI. Pekerjaan STIAMI dapat distandardisasi, sehingga dapat dilakukan perkembangan yang berkelanjutan.

Perbaikan administrasi menduduki prioritas kedua karena dengan adanya perbaikan administrasi yang otomatis diikuti perbaikan dokumentasi akan memberikan peningkatan proses pelayanan kepada users.

Tujuan ketiga yang hendak dicapai oleh STIAMI adalah referensi, dikarenakan adanya harapan semua unit yang berada dalam manajemen STIAMI mengimplementasi SMM ISO 9001:2008.

Hasil pengolahan pada level lima (alternatif tindakan) menunjukkan bahwa secara berurutan alternatif tindakan yang dapat dilakukan untuk membuat implementas SMM ISO 9001:2008 berjalan efektif adalah Pendidikan dan Pelatihan $(38,8 \%)$, Monitoring dan Evaluasi $(33,4 \%)$ dan teamwork $(27,8 \%)$ seperti yang terlihat pada Tabel 7. 
Tabel 7 Susunan prioritas alternatif tindakan

\begin{tabular}{ccc}
\hline Alternatif Tindakan & Bobot & Prioritas \\
\hline Pendidikan dan Pelatihan (Diklat) & $38,8 \%$ & 1 \\
Monitoring dan Evaluasi (Monev) & $33,4 \%$ & 2 \\
Teamwork (kerjasama) & $27,8 \%$ & 3 \\
\hline
\end{tabular}

Sumber: Hasil analisis AHP

Prioritas pertama dalam alternatif yang dilakukan oleh STIAMI adalah diklat. Kegiatan ini dilakukan untuk memberikan pemahaman kepada karyawan mengenai SMM. Kurangnya sosialisasi menyebabkan rendahnya pemahaman karyawan terhadap sistem mutu yang berdampak pada kurangnya keinginan untuk mendukung implementasi sistem mutu yang ada. Selain itu, kegiatan diklat dapat dilakukan secara berkala untuk meningkatkan pola pikir karyawan, agar mampu bekerja dengan mengedepankan mutu untuk mendukung implementasi SMM ISO 9001:2008.

Prioritas kedua yang harus dilakukan adalah monev. Monitoring untuk melihat kemajuan kinerja implementasi SMM ISO 9001:2008 secara periodik untuk tindakan korektif dan evaluasi untuk menilai hasil implementasi SMM ISO 9001:2008 untuk perbaikan program selanjutnya.

Prioritas ketiga yang harus dilakukan adalah teamwork (kerja sama). Dengan adanya kerja sama antar pihak yang berkaitan dengan implementasi SMM ISO 9001:2008, maka akan terjadi implementasi SMM yang baik sehingga target atau tujuan yang telah ditentukan akan tercapai.

\section{IMPLIKASI MANAJERIAL}

Hasil penelitian ini dapat memberikan informasi yang berguna bagi pihak STIAMI Jakarta dalam upaya memelihara implementasi SMM ISO 9001:2008, yakni didapatkan tiga alternatif tindakan, yaitu: (1). Prioritas yang pertama dengan nilai bobot $38,8 \%$ adalah diklat dengan tujuan memperbaiki tingkat pemahaman karyawan terhadap SMM yang dilakukan organisasi. Bentuk dari tindakan tersebut adalah dilakukannya pelatihan ISO 9001:2008 minimal satu kali setahun kepada karyawan. Dengan diklat tersebut diharapkan dapat meningkatkan pemahaman mengenai SMM, sehingga dapat memicu karyawan untuk berkerja dengan mindset ISO; (2) Prioritas yang kedua dengan nilai bobot $33,4 \%$ adalah monev dengan tujuan: (a) Melaksanakan pemantauan dan evaluasi terhadap kinerja STIAMI dan semua program studi dan memberikan umpan balik, (b) Merumuskan mekanisme monitoring dan evaluasi internal pada seluruh institusi: prodi, pengelola dan lembaga, (c) Melaksanakan monitoring dan evaluasi akademik secara berkala, (d) Upaya peningkatan mutu (penyelesaian permasalahan) berdasarkan evaluasi diri, (e) Memantau capaian sasaran mutu dan proses pencapaiannya, (f) Mengevaluasi hasil pencapaian yang ada dan tindak lanjutnya; (3) Prioritas yang ketiga dengan nilai bobot $27,8 \%$ adalah teamwork (kerja sama) dengan tujuan untuk membantu kelompok fungsional menjadi lebih efektif. Karena rasa individualisme dan persaingan antarpribadi relatif tajam dalam organisasi, secara spesifik, membangun sebuah tim artinya harus mengembangkan semangat, saling percaya, kedekatan, komunikasi, dan produktivitas.

Implementasi SMM ISO 9001:2008 pada STIAMI merupakan bentuk upaya peningkatan mutu berkelanjutan dalam mutu pendidikan tinggi, sehingga tercapainya tujuan pendidikan yang telah ditetapkan. Dengan implementasi 
ISO 9001:2008 yang efektif pada STIAMI, maka kegiatan penyelenggaraan program dan kegiatan lembaga baik dalam bidang akademik (pendidikan, penelitian dan pengabdian pada masyarakat) maupun nonakademik (administrasi dan manajemen) dapat berjalan sesuai dengan standar mutu yang telah ditetapkan. Dan untuk unit-unit di bawah manajemen STIAMI terutama diploma dan pascasarjana dapat tersertifikasi ISO 9001:2008.

\section{Simpulan}

Berdasarkan hasisl penelitian yang telah dilakukan, maka dapat diberi kesimpulan sebagai berikut: (1) Implementasi SMM ISO 9001:2008 pada STIAMI telah berjalan sejak tahun 2011, institusi telah mengimplementasikan sistem manajemen mutu dengan mengikuti aturan-aturan dasar, yang meliputi sistem dokumentasi, pemeliharaan, dan pengembangan sistem manajemen mutu. STIAMI mendokumentasikan sistem manajemen mutu yang terdiri dari empat tingkat hierarki dokumentasi; (2) Tanggung jawab manajemen dalam mengembangkan dan menjalankan sistem manajemen mutu, serta meningkatkan efektivitas implementasinya secara kontinu telah dipenuhi dan dijalankan oleh organisasi.

\section{Saran-Saran}

Berikut ini beberapa saran yang penulis untuk arah pengembangan selanjutnya. Saransaran berikutnya hanya merupakan ide secara garis besar: (1) Melakukan diklat secara intensif minimal 6 bulan sekali untuk menambah pemahaman karyawan mengenai SMM ISO 9001: 2008, sehingga dapat memicu karyawan untuk berkerja dengan mindset ISO. Dengan hal tersebut, maka kegiatan penjaminan mutu dapat berjalan dengan baik; (2) STIAMI perlu melaksanakan monitoring dan evaluasi secara berkala pada setiap program kerja yang ada dalam sasaran mutu dan melaksanakannya dengan sungguh-sungguh agar dapat memantau status implementasi SMM ISO 9001:2008 secara menyeluruh dalam upaya peningkatan mutu; (3) Hingga saat ini hanya STIAMI Pusat yang telah mengimplementasikan ISO 9001:2008. Unit utama yang berada dibawah manajemen STIAMI seperti Pascasarjana dan Diploma sebaiknya juga ikut serta dalam mengimplementasikan ISO 9001:2008.

\section{DAFTAR PUSTAKA}

Atmadi, S. 2010. Panduan Membangun Gugus Mutu. TANGERANG SELATAN: PT BERNAM CIPTA PERKASA.

Gaspersz, V. 2003. ISO 9001:200 And Continual Quality Improvement. Jakarta: PT. Gramedia Pustaka Utama.

Haberer dan Webb. 2010. Total Quality Management (Terjemahan). Jakarta: PT. Indeks.

Heizer, J. and B. Render. 1993. Production and Operations Management: Strategies and Tactics. New Jersey: Prentice Hall.

Hermawan, A. 2006. Penelitian Bisnis Paradigma Kuantitatif. Jakarta: Grasindo.

Marimin. 2004. Teknik dan Aplikasi Pengambilan Keputusan Kriteria Majemuk. Jakarta: Grasindo.

Patterson, J.G. 2010. ISO 9000 Standar Kualitas Seluruh Dunia (Terjemahan). Jakarta: PT. Indeks.

Purwoto, A. 2007. Panduan Lab Statistik Inferensial. Jakarta: Grasindo.

Saaty, T. L. 1991. Pengambilan Keputusan : Bagi Para Pemimpin (Terjemahan). Jakarta: PT. Pusaka Binaman Pressindo.

Saaty, T.L. 1993. Pengambilan Keputusan Bagi Para Pemimpin (Terjemahan). Jakarta: PT. Pustaka Binaman Pressindo.

Sallis, E. 2010. Total Quality Management in Education. Yogjakarta: IRCiSoD.

Sugiyono. 2006. Metode Penelitian Bisnis. Bandung: Alfabeta

Sugiyono. 2007. Metode Penelitian Kuantitatif Kualitatif dan $R \& D$. Bandung: Alfabeta

Sulistyo,Basuki. 1996. Pengantar Kearsipan. Jakarta: Universitas Terbuka. 
Syukur, A. 2010. 5R ISO 9001:2008 dan Poke Yoke Strategi Jitu Manajemen Mutu Perusahaan. Yogyakarta: Kata Buku.

Uma Sekaran dalam bukunya Research Methode for Business (1994, dalam Sugiyono, 2003)

Widodo, 2011. Manajemen Mutu Pendidikan. Jakarta: PT. Ardadizya Jaya.

Sumber lain:

Arief Maulana. 2011. "Analisis Penerapan Sistem Manajemen Mutu ISO 9001:2008 pada Kantor Manajemen Mutu Institut Pertanian Bogor". Skripsi pada Fakultas Ekonomi dan Manajemen, Institut Pertanian Bogor, Bogor.

Fahmy, Bassam. 2009. Pengantar Kearsipan dan Dokumentasi. Diunduh dari http://arsipdandok.blogspot.com/pengantarkearsipan-dan-dokumentasi.html. 17 Mei 2013.
Siti Nuraini. 2011. Kajian permasalahan Sistem Manajemen Mutu ISO 9001:2000 pada SMP Negeri 1 Kota Bogor. Skripsi pada Fakultas Ekonomi dan Manajemen, Institut Pertanian Bogor, Bogor.

Wangtry. 2009. Standar Mutu. http://wangtry.wordpress.com mutu/. [11 Februari 2011]

http://bonoes.blogspot.com/langkah-langkahpenerapan-iso.html, 5 Juli 2013

http://joko1234.wordpress.com/penelitiankualitatif-naturalistik, 2 September 2013

http://www.menulisproposalpenelitian.com/201 1/01/keabsahan-data-penelitiankualitatif.html, 1 Juni 2013

http://www.min-consulting, 15 Juli 2013 http://www.scm.aurino.com, 12 Juli 2013. 